Int. J. Dev. Biol. 53: 579-584 (2009)

doi: $10.1387 / \mathrm{ijdb} .082623 \mathrm{eh}$

\title{
Neurogenic and mitotic effects of dehydroepiandrosterone on neuronal-competent marrow mesenchymal stem cells
}

\author{
ESMAEIL H. SHIRI ${ }^{1,2}$, NARGES-ZARE MEHRJARDI ${ }^{1}$, MAHMOOD TAVALLAEI ${ }^{2}$, \\ SAEID K. ASHTIANI ${ }^{1}$ and HOSSEIN BAHARVAND*,1,3 \\ ${ }^{1}$ Department of Stem Cells, Cell Science Research Center, ACECR, Royan Institute, ${ }^{2}$ Department of Biology, Imam Hossein University \\ and ${ }^{3}$ Department of Developmental Biology, University of Science and Culture, ACECR, Tehran, Iran
}

\begin{abstract}
To establish whether dehydroepiandrosterone (DHEA) as a neurosteroid could enhance the rate of neuronal differentiation in neuronal-competent bone marrow mesenchymal stem cells (BM-MSCs), we added DHEA before and after plating the neurosphere-like aggregates. Flow cytometric analysis of Tubulin-III and Tau positive cells revealed that the percentages of these cells were increased significantly for the two markers following DHEA treatment at both stages. Moreover, Western blot analysis revealed that Tubulin-III protein was strongly induced by DHEA. The expression of neuronal specific genes such as IsI-1, Tubulin III, Pax6 and Nestin was also detected by RT-PCR analysis as well as BrdU incorporation and found to have increased significantly after DHEA induction. In conclusion, these results provide evidence that DHEA can affect neuronal-competent MSCs in inducing the expression of a comprehensive set of genes and proteins that define neuronal cells. DHEA was also able to induce the division of neuronalcompetent MSCs, thereby increasing the number of cells with major neuronal characteristics. To our knowledge, this is the first report which shows that DHEA can induce the division and differentiation of MSCs into neurons in vitro and should provide an improved basis for new treatments using MSCs of a wide variety of neurological diseases.
\end{abstract}

KEY WORDS: dehydroepiandrosterone, mesenchymal stem cell, neuronal differentiation

\section{Introduction}

Dehydroepiandrosterone (DHEA), its sulfate ester (DHEAS) and other related steroids as well as allopregnanolone (Allo) represent the most abundant steroid products of the adrenal cortex. They are found to be synthesized de novo in brain glial cells and their concentrations are particularly high in the brain and are therefore considered to be neurosteroids (Kaasik et al., 2001, Lapchak and Araujo, 2001, Marx et al., 2000). Moreover, DHEA levels have been found to decline in mental illnesses such as major depressive disorder or in systematic diseases that respond to DHEA supplementation (Bloch et al., 1999, Roshan et al., 1999). The decline of neurosteroid levels during aging may also leave the brain unprotected against neurotoxic challenges (Charalampopoulos et al., 2006b). DHEA has further been shown to be neuroprotective after oxidative stress in rat hippocampal neuronal cultures (Bastianetto et al., 1999) and hippocampal damage induced by N-methyl-D-aspartate (NMDA) (Kimonides et al., 1998) or chromaffin cells and the sympathoadrenal PC12 cells (an established model for the study of neuronal cell apoptosis and survival) against serum deprivation-induced apoptosis (Charalampopoulos et al., 2006a). Furthermore, it can directly stimulate biosynthesis and release of neuroprotective catecholamines, exerting a direct transcriptional effect on tyrosine hydroxylase and regulate actin depolymerization and submembrane actin filament disassembly, a fast-response cellular system regulating trafficking of catecholamine vesicles (Charalampopoulos et al., $2006 \mathrm{~b})$. DHEA can also affect the endocrine, immune, and metabolic systems (Bellino et al., 1995).

Recent studies have shown that mesenchymal stem cells (MSCs) derived from bone marrow cell suspensions can be

\footnotetext{
Abbreviations used in this paper: BM, bone marrow; DHEA, dehydroepiandrosterone; MSC, mesenchymal stem cell; NSC, neuronal stem cell.
}

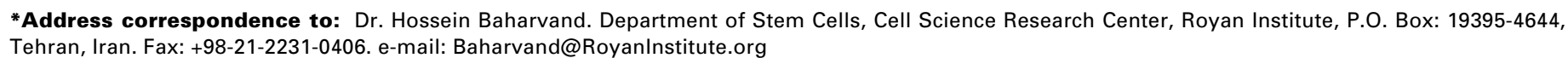


expanded by their selective attachment to plastic tissue culture dishes (Friedenstein et al., 1976, Reyes et al., 2001, Sekiya et al., 2002).

By far the most prominent advantage of using MSCs over other cell types in cell-replacement therapy is their autologous characteristic. In addition, these cells were reported to differentiate in vitro and in vivo into cells expressing neuronal and glial markers (Sanchez-Ramos et al., 2000, Woodbury et al., 2000, Zhao et al., 2002). It has also been shown that like embryonic stem cells (ESCs), adult human MSCs in the presence of epidermal growth factor (EGF) and basic-fibroblast growth factor (bFGF) can become converted into a clonogenic neuronal stem cell-like population growing in neurosphere-like structures also called marrowderived neuronal stem cells (mNSC). These can then be differentiated into cells with morphological and functional characteristics of neuronal, and glial cells in vitro (Hermann et al., 2004). Therefore MSCs provide an innovative model to understand developmental and molecular mechanisms of neurosteroid actions. Moreover, the use of MSCs in auto-graft protocols in neurological diseases necessitates the identification of the molecular events that are important for the induction of neuronal differentiation of MSCs. We have shown here that DHEA can induce the differentiation of neuronal cells from MSCs and increase their cell proliferation in vitro. These results have important implications for MSCs and are important in the understanding of DHEA actions on the process of neuronal differentiation from MSCs.

\section{Results and Discussion}

\section{MSC characterization}

MSCs were isolated from the femurs of adult mice and propagated in vitro as established previously in our laboratory (Eslaminejad et al., 2006). At low plating densities, MSCs grew as a monolayer of large, flat cells and made colony forming unitfibroblast (CFU-F, Fig. 1A). As the cells approached confluency, they assumed a more spindle-shaped and a fibroblastic morphology (Fig. 1B). Flow cytometric analysis at the passages (4-6) demonstrated that the cells were negative for CD11b (Fig. 1C), CD45 (Fig. 1D), CD 34 (Fig. 1E), Oct-4 (Fig. 1F), cell surface markers associated with lymphohematopoietic cells and cell nuclear marker associated with multipotential adult progenitor cells (MAPCs). The MSCs did express CD44 (Fig. 1G) and Sca1 (Fig. $1 \mathrm{H})$, consistent with their undifferentiated state.

\section{Neuronal Differentiation}

To convert MSCs into cells with characteristics of NSCs, we detached the MSCs after 4-6 passages and cultured them in 1\% agarose-coated dishes in serum-free neurobasal medium supplemented with bFGF+EGF. The cells did not adhere to the surface of culture dishes and formed small spheres of floating cells (Fig. 2 A,B) and finally made mNSCs in vitro. Immunocytochemistry showed that mNSCs in the presence of only bFGF+EGF expressed high levels of Nestin (Fig. 2C). The flow cytometric analysis showed that Nestin expression in MSCs increased from $27.5 \pm 2.1$ to $77.5 \pm 0.6(P<0.001$, Fig. 2D) in day 7 and decreased in day 11 to $62.5 \pm 1.5(P<0.001$, Fig. $2 D)$. Therefore in order to confirm the differentiation potential of these cells, neurosphereslike aggregates were dissociated and plated to poly-L-lysine coated plates for 12 days under differentiating conditions. We first asked what role DHEA may play in the neuronal differentiation of MSCs in culture. To establish whether DHEA could enhance the differentiation rate, we added different concentration of DHEA $(0.1,1.0$ and $10 \mu \mathrm{M})$ with and without RA $(1 \mu \mathrm{M})$ at the plating stage. Within 4 to 12 days after plating, changes in the morphology of responsive cells assuming neuronal identity became apparent. These morphological changes were similar to those reported previously (Hermann et al., 2004), in which the cytoplasm in the flat cells was initially retracted towards the nucleus, forming a contracted multipolar cell body leaving membranous processes like peripheral extensions. Over the subsequent days, the cell bodies became increasingly spherical and retractile, exhibiting a typical neuronal perikaryal appearance. Gradually, MSCs-derived neurons displayed distinct neuronal morphologies ranging from simple bipolar to large, extensively branched multipolar cells (Fig. 2E), making conncetions via their processes (Fig. $2 \mathrm{~F}$ ). Some of the differentiated cells also acquired morphological and phenotypical characteristics of astrocytes (Fig. 2G). Following the fixation process, the cells were immunostained for the neuronal markers; Tubulin-III (Fig. 2H) and Tau (Fig. 2I), as well as the astrocyte marker; GFAP (Fig. 2J). The results further verified the presence of many well differentiated neurons and astrocytes. Moreover, the expression of neuronal specific genes such as Isl-1, Tubulin III, Pax6, and Nestin were also studied by RT-PCR analysis (Fig. 2K) in which they were found to be weakly expressed in MSCs. Westren blot analysis using anti-Tubulin III antibody revealed that Tubulin-III protein was only induced strongly following the DHEA addition (Fig. 2L). The expression of neuronal markers in mouse bone marrow-derived MSCs has been reported in the past where the MSCs were found to express certain neuronal phenotype markers spontaneously in the absence of specialized induction reagents in culture. These cells were believed to be probably «primed» toward a neuronal fate by the constitutive expression of neuronal antigens and seemed to
Fig. 1. Characterization of cultured mouse MSCs. At low plating densities, MSCs grew as a monolayer of large, flat cells and made colony forming unit-fibroblasts (CFU-F, lines) (A). As the cells approached confluency, they assumed a more spindle-shaped, fibroblastic morphology (B). Flow cytometric analysis at passage number 4-6 demonstrated that the cells were negative for $C D 11 b$ (C), and CD45 (D), CD 34 (E), and Oct-4 (F), while CD44 (G) and Sca-1 were still expressed $\mathbf{( H )}$.
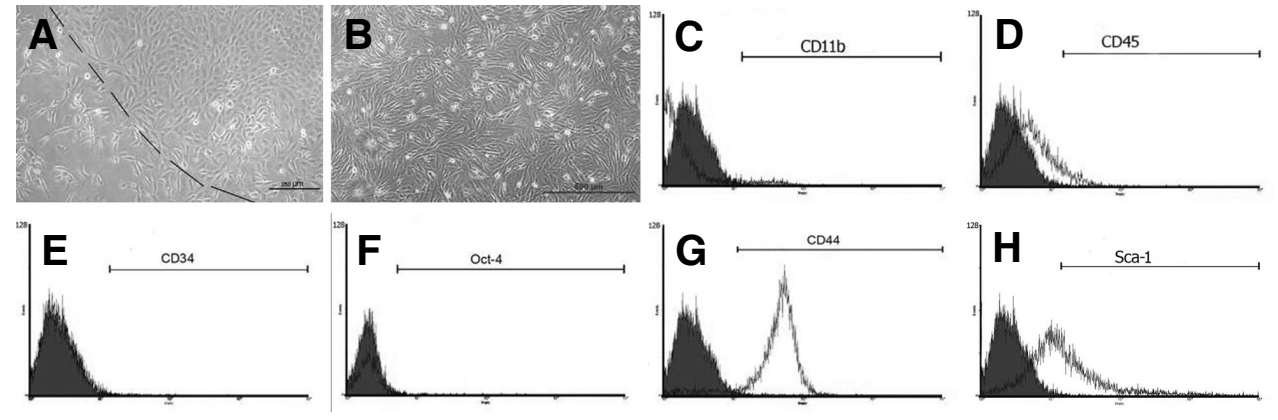

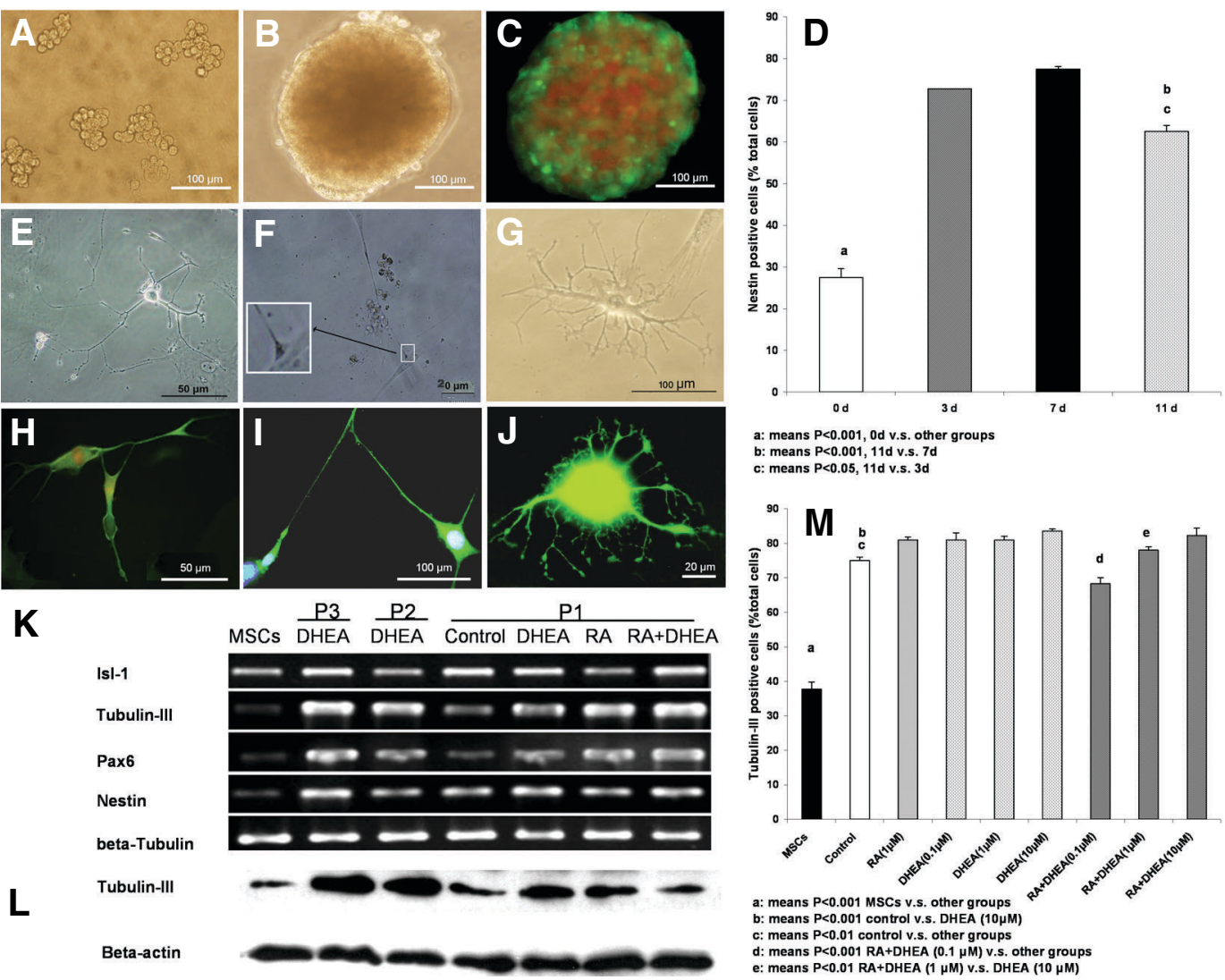

Fig. 2. Characterization of mouse MSC-derived neuronal-like cells. To convert MSCs into cells with characteristics of NSCs, MSCs were cultured in agarose-coated dishes in serum-free neurobasal medium supplemented with bFGF+EGF to form small floating spheres (A) and finally formed neurosphere-like aggregates containing mNSCs (B). Immunocytochemistry showed that mNSCs expressed high levels of nestin (C) and the flow cytometric analysis showed that nestin expression increased by differentiation of MSCs up to day 7 and decreased on day 11 (D). The plated neurosphereslike aggregates, displayed gradually distinct neuronalmorphologies ranging from simple bipolar, to large extensively branched multipolar cells (E) and making connections via their processes (F). Some of the differentiated cells however acquired morphological and phenotypical characteristics of astrocytes (G). Immunocytochemistry of the differentiated cells showed the expression of Tubulin-III (H) and Tau (I), mature neuron markers and GFAP (J), astrocyte marker. The nuclei were conterstained with propidium $(H, J)$ and DAPI (I). Moreover, the expression of neuronal specific genes such as Isl-1, Tubulin-III, Pax6, and Nestin were determined by RT-PCR analysis (K). Western blot analysis using anti-Tubulin III antibody revealed that Tubulin-III protein was strongly induced by only DHEA (L). The analysis of Tubulin-III positive cells by flow cytometry of the cells after DHEA treatment in plating stage revealed that the percentage of these cells was increased significantly following the DHEA or RA treatment (at least $P<0.01$ ), (M) and this difference was not significant between different concentrations of DHEA (0.1, 1.0 and $10 \mu \mathrm{M})$. However, only high concentration of RA+DHEA improved neuronal-like cells differentiation in comparison with $R A+D H E A(0.1$ or $1 \mu \mathrm{M})$.

respond with an appropriate neuronal pattern of differentiation, when exposed to the environment of the developing brain (Deng et al., 2006).

The analysis of Tubulin-III positive cells by flow cytometry revealed that the percentage of these cells was increased significantly following DHEA or RA treatment (at least $P<0.01$, Fig. $2 M$ ) and that there was no significant differences between different concentrations of DHEA $(0.1,1.0$ and $10 \mu \mathrm{M})$. We therefore continued our experiments with $1 \mu \mathrm{M}$ DHEA but found that only the highest concentration of DHEA $(10 \mu \mathrm{M})$ when used with RA treatment improved the neuronal differentiation and not the DHEA (0.1 or $1 \mu \mathrm{M})$ or RA alone (Fig. $2 \mathrm{M})$.

To assess the DHEA influence in the stage of neurosphereslike aggregate formation and the effect of $b F G F+E G F, D H E A$ was added in either the presence or absence of bFGF+EGF in culture. Flow cytometric analysis of Tubulin-III and Tau positive cells after plating, revealed that the percentage of these cells was increased significantly for the two markers following DHEA treatment at both the neurosphere-like aggregate formation stage (protocol 2 and 3 ) and plating stage (protocol 1) (at least $P<0.01$, Fig. 3). The percentage increase in these markers following DHEA treatment and bFGF+EGF however, was not found to be significant. Moreover, Western blot analysis revealed that Tubulin-III protein was strongly induced by only DHEA in the neurosphere-like aggregate formation stage with or without bFGF+EGF in comparison with addition of DHEA in the plating stage (Fig. 2L).

DHEA has also been shown to be a potential signaling molecule in neuronal differentiation during development (Compagnone and Mellon, 1998) and has recently been shown to increase neurogenesis in the adult rodent hippocampus (Karishma and Herbert, 2002). DHEA is also found to be involved in the maintenance and division of human NSC cultures derived from the fetal cortex (Suzuki et al., 2004). Moreover, it is reported that DHEA enhances the differentiating effect of RA on neuroblastoma cells via a signalling pathway that is not $R A$ receptor-mediated (Silvagno et al., 2002).

To evaluate the possible mechanism of DHEA function, it was administrated in the neurosphere-like aggregate formation stage with and without bFGF+EGF (protocol 3 and 2, respectively). The diameter of neurosphere-like aggregates was found to increase significantly when DHEA used at this stage $(P<0.001)$ in either the presence or absence of $\mathrm{bFGF}+\mathrm{EGF}$ (Fig. $4 \mathrm{~A}$ ). To evaluate this enhancement, BrdU incorporation assay were performed with $\mathrm{mNSC}$ after DHEA induction at day 7 in the presence or absence of bFGF+EGF (Fig. 4B1, 4B2, 4C1, 4C2, 4D1, 4D2). Approximately $87.9 \pm 2.4 \%$ of DHEA stimulated mNSCs exhibited BrdUpositive cellular nuclei with bFGF+EGF in comparison with the control (without DHEA, 75.8 $\pm 5.0 \%, P<0.001$ ). However, only 


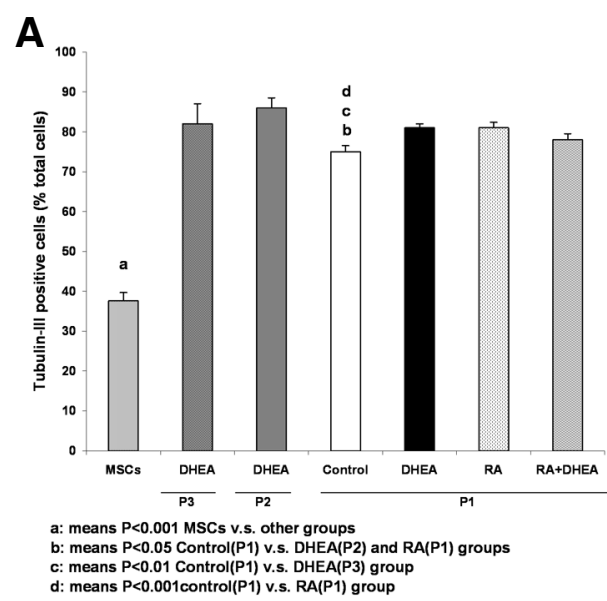

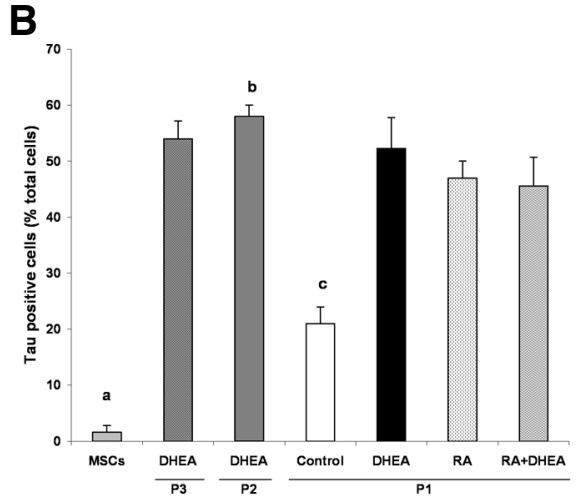

a: means $P<0.001$ MSCs v.s. other groups b: means $P<0.01$ DHEA (P2) group v.s. RA(P1) and RA+DHEA(P1) groups $c$ : means $P<0.001$ control(P1) group $v$.s. other groups
Fig. 3. Flow cytometric analysis of MSCderived neuronal-like cells under different treatments. Flow cytometric analysis of Tubulin-III (A) and Tau (B) positive cells after plating revealed that the percentages of these cells were increased significantly for the two markers following DHEA treatment in both stages at the neurosphere-like aggregate formation stage (protocol 2 and 3) or plating stage (protocol 1) (at least $P<0.01)$. $P$ : protocol.
$72.4 \pm 3.3 \%$ of $\mathrm{mNSCs}$ without $\mathrm{bFGF}+\mathrm{EGF}$ and in the presence of DHEA (protocol 3) were positive for BrdU staining, $(P<0.001$ vs other groups, Fig. 4E). Therefore the BrdU incorporation has increased significantly in the presence of bFGF+EGF by DHEA and these data also show that DHEA has selectively increased the division of the cells responsive to bFGF+EGF within the neurosphere-like aggregates.

In general neurosteroids possess the ability to effect neurons through activation of $\gamma$-aminobutyric acid (GABA), NMDA, and sigma receptors (Baulieu, 1997, Baulieu, 1998, Suzuki et al., 2004, Xilouri et al., 2007, Xilouri and Papazafiri, 2006), however the exact role of each factor with regard to DHEA is not well established. Moreover, the prosurvival effect of DHEA appears to be mediated by G-protein-coupled-specific membrane binding sites (Charalampopoulos et al., 2006a). This involves the antiapoptotic $\mathrm{Bcl}-2$ proteins, the activation of prosurvival transcription factors; CREB and NF-kappaB and the expression of upstream effectors of the antiapoptotic $\mathrm{Bcl}-2$ protein, as well as a posttranslational activator of $\mathrm{Bcl}-2$; the prosurvival kinase PKCalpha/beta, (Charalampopoulos et al., 2006b). The neuroprotection also involves phosphorylation of the prosurvival factor Src and the induction of the anti-apoptotic protein $\mathrm{Bcl}-2$ (Charalampopoulos et al., 2006a). DHEA is found to inhibit excitotoxic cell death of $\mathrm{P} 19-\mathrm{N}$ neurons, by directly maintaining the activation of $\mathrm{PKB} / \mathrm{Akt}$ kinase and interfering with the intrinsic mitochondrial apoptotic pathway, preserving cytochrome $\mathrm{C}$ in the mitochondria and Bax in the cytoplasm (Xilouri et al., 2007).

Taken together, these results have shown that DHEA can
Fig. 4. Cell proliferation after DHEA treatment. To evaluate the possible mechanism of DHEA, the diameter of neurosphere-like aggregates increased significantly when DHEA administrated at the neurospheres-like aggregate formation stage with and without bFGF+EGF (protocol 3 and 2, respectively) $(P<0.001)$ in presence or absence of $b F G F+E G F(\mathbf{A})$. To evaluate this enhancement, BrdU incorporation assays were performed with $\mathrm{mNSCS}$ after DHEA induction at day 7 in the presence or absence of b $F G F+E G F(\mathbf{B}-\mathbf{E})$. Immunostaining $(B, C, D)$ and flow cytometry analysis (E) of the differentiated cells with anti-BrdU showed in the presence of bFGF+EGF, DHEA significantly increased $\mathrm{BrdU}$ incorporation (protocol 2, B: $D H E A+b F G F+E G F, C:+b F G F+E G F)$. However, in absence of bFGF+EGF, DHEA did not increase BrdU-positive cellular nuclei (protocol 3, D: only $D H E A)$. These data show DHEA selectively increases the division of the bFGF+EGF-responsive cells within the neurosphere-like aggregates (E). The nuclei were counterstained with DAPI (B2, C2, D2).
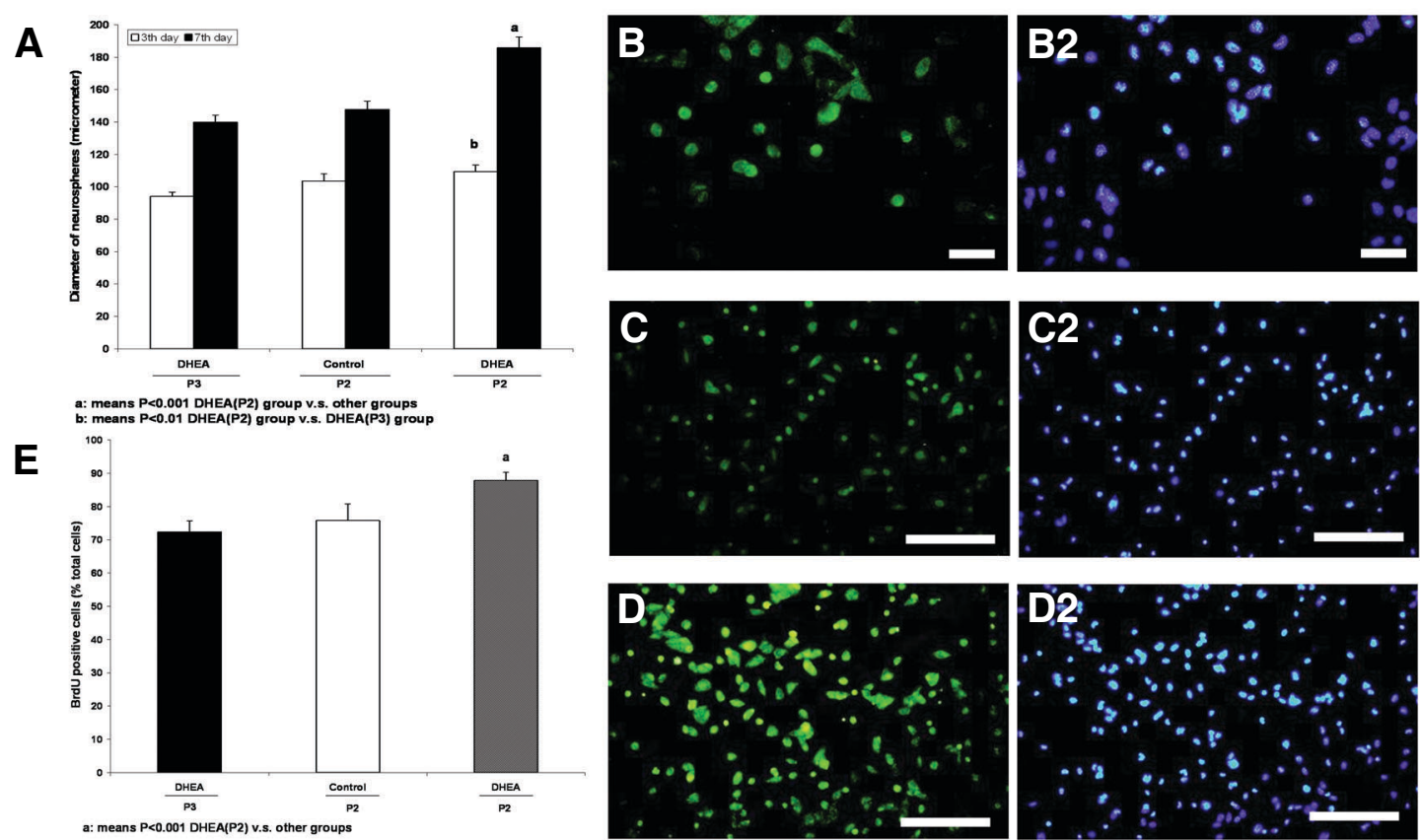
induce the expression of a comprehensive set of genes and proteins that define neuronal cell identity in neuronal-competent MSCs forming mNSCs. Moreover, our results suggest that DHEA can induce the division of mNSCs and so increase the number of cells with major neuronal-like characteristics. To our knowledge, this is the first report that DHEA has been shown to induce the division and differentiation of MSCs into neuron-like cells in vitro, when added at either the neurosphere-like aggregate formation stage and/or the plating stage. MSCs may therefore be useful in the treatment of a wide variety of neurological diseases, offering significant advantages over other "stem" cells. The marrow cells are readily accessible, overcoming the risks of obtaining either NSCs from the brain or ESCs from preimplantation embryos while also provide a renewable population of cells.

\section{Materials and Methods}

\section{Culture and expansion of MSCs}

Mouse MSCs were cultured in Dulbecco modified Eagle's medium (DMEM) supplemented with $10 \%$ fetal calf serum (FCS), $1 \%$ penicillin/ streptomycin, and $2 \mathrm{mM} \mathrm{L-glutamine.} \mathrm{They} \mathrm{were} \mathrm{grown} \mathrm{to} \mathrm{confluency}$ before being detached by Trypsin/EDTA treatment and were seeded at $1 \diamond 10^{4} \mathrm{cell} / \mathrm{cm}^{2}$ in culture flasks before being evaluated for their multipotency while differentiating into chondrocytes, adipocytes, and osteoblasts (Eslaminejad et al., 2006). All aforementioned materials were purchased from Invitrogen-Gibco.

\section{Neuronal Induction}

MSCs were dissociated with $0.05 \%$ trypsin/0.04\% EDTA and cultured on agarose (Sigma-Aldrich)-coated dishes ( $60 \mathrm{~mm}$, Nunc) at a concentration of $1 \times 10^{5} \mathrm{cells} / \mathrm{ml}$ in neurobasal medium containing B27 ( $2 \%$, Invitrogen-Gibco), 1\% insulin-transferrin-selenite (ITS, Invitrogen-Gibco), Lglutamine, $1 \%$ penicillin/streptomycin supplemented with $20 \mathrm{ng} / \mathrm{ml}$ of both EGF and bFGF (both from Sigma-Aldrich) at 5\% CO2.

Induction of terminal neuronal differentiation was initiated by plating the cells on poly-L-lysine- (Sigma-Aldrich) coated plates at a concentration of $3 \times 10^{4} \mathrm{cells} / \mathrm{cm}^{2}$ in the same medium without bFGF+EGF and in presence of $10 \%$ FCS and $1 \mu \mathrm{M}$ all-trans-retinoic acid (RA, SigmaAldrich). Cells were differentiated for 12 day and the medium was changed every four days. DHEA was added in plating stage (protocol 1) or in neurospheres-like stage in presence (protocol 2) and/or absence (protocol 3) of bFGF+EGF (Table 1).

\section{Immunofluorescence staining}

Cultured cells were fixed with $4 \%$ paraformaldehyde (Sigma-Aldrich)

TABLE 1

\section{DIFFERENTIATION INDUCTION PROTOCOL OF NEURONAL-LIKE CELLS FROM MSC}

\begin{tabular}{llclll} 
MSCs & \multicolumn{3}{c}{ Neurosphere formation (7d) } & & Plating and Maturation (5d) \\
\hline Protocol 1 & $\rightarrow$ & + (bFGF+EGF) & $\rightarrow$ & $\begin{array}{l}+/ \text {-DHEA }(0.1,1,10 \mu \mathrm{M}) \\
+\mathrm{RA}\end{array}$ \\
Protocol 2 & $\rightarrow$ & $\begin{array}{c}+(\mathrm{bFGF}+\mathrm{EGF}) \\
+/ \text { DHEA }(1 \mu \mathrm{M})\end{array}$ & $\rightarrow$ & \\
Protocol 3 & $\rightarrow$ & $+\operatorname{DHEA}(1 \mu \mathrm{M})$ & $\rightarrow$ & \\
\hline
\end{tabular}

MSCs were cultured in $1 \%$ agarose-coated dishes in serum-free neurobasal medium supplemented with (protocol 1 and 2) or without (protocol 3) bFGF+EGF to form small spheres of floating cells and finally made marrow-derived NSC-like cells in vitro. To establish whether DHEA could enhance differentiation rates, we added different concentration of DHEA $(0.1,1.0$ and $10 \mu \mathrm{M})$ (protocol 1). To assess the stage of DHEA influence or its effect along with bFGF+EGF, DHEA was added in the presence (protocol 2) and absence (protocol 3) of bFGF+EGF during the neurospheres-like aggregate formation stage. In all protocols, cells were differentiated for 12 days. and rinsed with PBS (Invitrogen-Gibco)-Tween20 (Sigma-Aldrich). The cells were permeabilized by $0.5 \%$ Triton $X-100$ and blocked with $10 \%$ normal serum produced from the same species as the secondary antibody. This was followed by an overnight incubation with primary antibodies including anti-Nestin (Chemicon, MAB353, 1:100), anti- $\beta$-Tubulin-III (Sigma-Aldrich, T5293, 1:200), anti-Tau (Millipore, MAB5270, 1:400), anti-BrdU (Roche, 11296736001, 1:200), and anti-glial fibrillary acidic protein (GFAP, Chemicon, MAB3402, 1:400). After rinsing, samples were incubated with secondary antibody: fluorescein isothiocyanate (FITC)conjugated anti-mouse (Chemicon, AP308, 1:250) and the cells which were labeled with FITC were counterstained with 4,6-diamidino-2phenylindole (DAPI, Sigma-Aldrich, D-8417, $0.02 \mu \mathrm{g} / \mathrm{ml}$ ) and $/ \mathrm{or} 1 \mu \mathrm{g} / \mathrm{ml}$ propidium iodide (PI, Sigma-Aldrich, P4864) for 3 min at room temperature. Omission of the primary antibody in the sample was used as a control for all markers. Labeled cells were examined with a fluorescence microscope (Olympus, BX51, Japan) and images were acquired with an Olympus D70 camera.

\section{Flow cytometric analysis}

All staining reactions were performed in staining buffer consisting of PBS supplemented with $2 \%$ FCS. After determination of the viability of the cells by trypan blue exclusion, cells were washed two times in staining buffer and fixed in $4 \%$ paraformaldehyde and triton X-100 $0.5 \%$ was used for permeabiliztion. Non-specific antibody binding was blocked with a combination of $10 \%$ heat-inactivated goat serum in staining buffer and 1 $1.5 \times 10^{5}$ cells were used per sample. Cells were incubated with the appropriate primary antibodies or appropriate isotype matched controls (Dako, X0927, 1:100). Primary antibodies used here were: anti-Nestin (1:20), anti- $\beta$-Tubulin III (1:200), anti-Tau (1:400), and anti-BrdU (1:100). The cells were washed two times in staining buffer and incubated for 30 min at $4^{\circ} \mathrm{C}$ with FITC-conjugated secondary antibody. After washing, flow cytometric analysis was performed with a BD-FACS Calibur Flow Cytometer. The experiments were replicated three times and the acquired data was analyzed by using the WinMDI (2.9) software.

\section{RNA extraction and RT-PCR analysis}

Total cellular RNA was extracted from the cells in different stages using total RNA (Nucleospin ${ }^{\circledR}$ ) purification kit followed by treatment with RNase-free DNase (Qiagen, Hilden, Germany). Standard RT was performed using $2 \mu \mathrm{g}$ total RNA, oligo (dT), and the RevertAid ${ }^{\mathrm{TM}}$ First Strand cDNA Synthesis Kit (Fermentas) according to the manufacturer's instructions. The cDNA samples were subjected to polymerase chain reaction (PCR) amplification using mouse specific primers. Amplification conditions were as follows: Initial denaturation at $94{ }^{\circ} \mathrm{C}$ for $5 \mathrm{~min}, 35$ cycles of denaturation at $94{ }^{\circ} \mathrm{C}$ for $30 \mathrm{sec}$, annealing at $55-70{ }^{\circ} \mathrm{C}$ for $45 \mathrm{sec}$ (see Table 2 for temperatures used) and extension at $72^{\circ} \mathrm{C}$ for $45 \mathrm{sec}$, followed by a final extension at $72^{\circ} \mathrm{C}$ for $10 \mathrm{~min}$. The PCR products were analyzed by gel electrophoresis on a $1.7 \%$ agarose gel stained with ethidium bromide $(1 \mu \mathrm{g} / \mathrm{ml})$ after which they were visualized and photographed on

TABLE 2

\section{PRIMERS AND THE REACTION CONDITIONS OF RT-PCR}

\begin{tabular}{llccc} 
Genes & Primer sequences (5'-3') & $\begin{array}{c}\text { Size } \\
\text { (bp) }\end{array}$ & $\begin{array}{c}\text { Annealing } \\
\text { Temperature }\end{array}$ & $\begin{array}{c}\text { Accession } \\
\text { No. }\end{array}$ \\
\hline Isl-1 & $\begin{array}{l}\text { F: GACTTTGAGCAAGGGGTTACG } \\
\text { R: ACATGAAAAGTGCAAGTCTCC }\end{array}$ & 439 & 60 & NM-021459 \\
$\beta-T u b u l i n$ III & $\begin{array}{l}\text { F: GTTCCCACGTCTCCACTTCTTC } \\
\text { R: CCAGGTCATTCATGTTGCTCTC }\end{array}$ & 479 & 63 & NM-023279 \\
Pax6 & $\begin{array}{l}\text { F: GAGAGGACCCATTATCCAGATG } \\
\text { R: GCTGACTGTTCATGTGTGTTTG }\end{array}$ & 467 & 61 & NM-013627 \\
Nestin & $\begin{array}{l}\text { F: TCGAGCAGGAAGTGGTAGG } \\
\text { R: TTGGGACCAGGGACTGTTA }\end{array}$ & 352 & 58 & NM-016701 \\
$\beta-$-Tubulin & $\begin{array}{l}\text { F: TCACTGTGCCTGAACTTACC } \\
\text { R: GGAACATAGCCGTAAACTGC }\end{array}$ & 317 & 58 & NM-011655 \\
\hline
\end{tabular}


gel documentation system (UVidoc, UK). A description of primers and the sizes of their final products are described in Table 2.

\section{Western blot Analysis}

Twenty micrograms of protein extracted from the cells at different stages was separated by $10 \%$ SDS-PAGE electrophoresis using a MiniPROTEAN 3 electrophoresis cell (Bio-Rad). Proteins were transferred to a nitrocellulose membrane (Bio-Rad) by semidry blotting (Bio-Rad) using Dunn carbonate transfer buffer $(10 \mathrm{mM} \mathrm{NaCHO} 3,3 \mathrm{mM} \mathrm{Na} 2 \mathrm{CO} 3$, and $20 \%$ methanol) and membranes were blocked for $1.5 \mathrm{~h}$ using Western blocker solution (Sigma-Aldrich, W0138) before being incubated with an antibody against $\beta$-Tubulin III (1:200) or anti-actin (Sigma-Aldrich, A5441, 1:5000). After washing, the membranes were incubated with the peroxidase-conjugated secondary antibody goat anti mouse horse reddish peroxidase (Sigma-Aldrich, A9044, 1:80).

\section{Diameter of neurosphere-like aggregates}

The diameter of neurosphere-like aggregates was measured under phase contrast inverted microscope (Olympus, Japan) using an Olysia Bioreport software in days 3 and 7.

\section{Statistical analysis}

The experiments were replicated at least three times. The data were expressed as mean \pm SD (standard deviation). One-way ANOVA followed by the Tukey post hoc test multiple group comparison was used to analyze group differences of the data collected from flow cytometric analysis. The difference between groups was then considered to be statistically reliable if the value of $\mathrm{P}<0.05$ was obtained.

\section{Acknowledgement}

This study was funded by the grant provided from the Royan Institute and the Iran National Science Foundation. We gratefully thank Dr. N.F. Dolatshad for her manuscript proofreading.

\section{References}

BASTIANETTO, S., RAMASSAMY, C., POIRIER, J. and QUIRION, R. (1999). Dehydroepiandrosterone (DHEA) protects hippocampal cells from oxidative stress-induced damage. Brain Res Mol Brain Res 66: 35-41.

BAULIEU, E.E. (1997). Neurosteroids: of the nervous system, by the nervous system, for the nervous system. Recent Prog Horm Res 52: 1-32.

BAULIEU, E.E. (1998). Neurosteroids: a novel function of the brain. Psychoneuroendocrinology 23: 963-987.

BELLINO, F.L., DAYNES, R.A., HORNSBY, P.J., LAVRIN, D.H. and NESTLER, J.E. (1995). Dehydroepiandrosterone (DHEA) and Aging. N.Y. Acad. Sci., New York.

BLOCH, M., SCHMIDT, P.J., DANACEAU, M.A., ADAMS, L.F. and RUBINOW, D.R. (1999). Dehydroepiandrosterone treatment of midlife dysthymia. Biol Psychiatry 45: 1533-1541.

CHARALAMPOPOULOS, I., ALEXAKI, V.I., LAZARIDIS, I., DERMITZAKI, E. AVLONITIS, N., TSATSANIS, C., CALOGEROPOULOU, T., MARGIORIS A.N., CASTANAS, E. and GRAVANIS, A. (2006a). G protein-associated, specific membrane binding sites mediate the neuroprotective effect of dehydroepiandrosterone. Faseb J 20: 577-579.

CHARALAMPOPOULOS, I., ALEXAKI, V.I., TSATSANIS, C., MINAS, V., DERMITZAKI, E., LASARIDIS, I., VARDOULI, L., STOURNARAS, C., MARGIORIS, A.N., CASTANAS, E. et al. (2006b). Neurosteroids as endogenous inhibitors of neuronal cell apoptosis in aging. Ann N Y Acad Sci 1088: 139-152.

COMPAGNONE, N.A. and MELLON, S.H. (1998). Dehydroepiandrosterone: a potential signalling molecule for neocortical organization during development.
Proc Natl Acad Sci U S A 95: 4678-4683.

DENG, J., PETERSEN, B.E., STEINDLER, D.A., JORGENSEN, M.L. and LAYWELL, E.D. (2006). Mesenchymal stem cells spontaneously express neural proteins in culture and are neurogenic after transplantation. Stem Cells 24: 1054-1064.

ESLAMINEJAD, M.B., NIKMAHZAR, A., TAGHIYAR, L., NADRI, S. and MASSUMI, M. (2006). Murine mesenchymal stem cells isolated by low density primary culture system. Dev Growth Differ 48: 361-370.

FRIEDENSTEIN, A.J., GORSKAJA, J.F. and KULAGINA, N.N. (1976). Fibroblast precursors in normal and irradiated mouse hematopoietic organs. Exp Hematol 4: 267-274.

HERMANN, A., GASTL, R., LIEBAU, S., POPA, M.O., FIEDLER, J., BOEHM, B.O. MAISEL, M., LERCHE, H., SCHWARZ, J., BRENNER, R. et al. (2004). Efficient generation of neural stem cell-like cells from adult human bone marrow stromal cells. J Cell Sci 117: 4411-4422.

KAASIK, A., KALDA, A., JAAKO, K. and ZHARKOVSKY, A. (2001). Dehydroepiandrosterone sulphate prevents oxygen-glucose deprivation-induced injury in cerebellar granule cell culture. Neuroscience 102: 427-432.

KARISHMA, K.K. and HERBERT, J. (2002). Dehydroepiandrosterone (DHEA) stimulates neurogenesis in the hippocampus of the rat, promotes survival of newly formed neurons and prevents corticosterone-induced suppression. Eur $J$ Neurosci 16: 445-453.

KIMONIDES, V.G., KHATIBI, N.H., SVENDSEN, C.N., SOFRONIEW, M.V. and HERBERT, J. (1998). Dehydroepiandrosterone (DHEA) and DHEA-sulfate (DHEAS) protect hippocampal neurons against excitatory amino acid-induced neurotoxicity. Proc Natl Acad Sci U S A 95: 1852-1857.

LAPCHAK, P.A. and ARAUJO, D.M. (2001). Preclinical development of neurosteroids as neuroprotective agents for the treatment of neurodegenerative diseases. Int Rev Neurobiol 46: 379-397.

MARX, C.E., JARSKOG, L.F., LAUDER, J.M., GILMORE, J.H., LIEBERMAN, J.A. and MORROW, A.L. (2000). Neurosteroid modulation of embryonic neuronal survival in vitro following anoxia. Brain Res 871: 104-112.

REYES, M., LUND, T., LENVIK, T., AGUIAR, D., KOODIE, L. and VERFAILLIE, C.M. (2001). Purification and ex vivo expansion of postnatal human marrow mesodermal progenitor cells. Blood 98: 2615-2625.

ROSHAN, S., NADER, S. and ORLANDER, P. (1999). Review: Ageing and hormones. Eur J Clin Invest 29: 210-213.

SANCHEZ-RAMOS, J., SONG, S., CARDOZO-PELAEZ, F., HAZZI, C., STEDEFORD, T., WILLING, A., FREEMAN, T.B., SAPORTA, S., JANSSEN, W., PATEL, N. et al. (2000). Adult bone marrow stromal cells differentiate into neural cells in vitro. Exp Neurol 164: 247-256.

SEKIYA, I., LARSON, B.L., SMITH, J.R., POCHAMPALLY, R., CUI, J.G. and PROCKOP, D.J. (2002). Expansion of human adult stem cells from bone marrow stroma: conditions that maximize the yields of early progenitors and evaluate their quality. Stem Cells 20: 530-541.

SILVAGNO, F., GUARNIERI, V., CAPIZZI, A. and PESCARMONA, G.P. (2002). Synergistic effect of retinoic acid and dehydroepiandrosterone on differentiation of human neuroblastoma cells. FEBS Lett 532: 153-158.

SUZUKI, M., WRIGHT, L.S., MARWAH, P., LARDY, H.A. and SVENDSEN, C.N (2004). Mitotic and neurogenic effects of dehydroepiandrosterone (DHEA) on human neural stem cell cultures derived from the fetal cortex. Proc Natl Acad Sci U S A 101: 3202-3207.

WOODBURY, D., SCHWARZ, E.J., PROCKOP, D.J. and BLACK, I.B. (2000). Adult rat and human bone marrow stromal cells differentiate into neurons. J Neurosci Res 61: 364-370.

XILOURI, M., AVLONITIS, N., CALOGEROPOULOU, T. and PAPAZAFIRI, P. (2007). Neuroprotective effects of steroid analogues on P19-N neurons. Neurochem Int 50: 660-670.

XILOURI, M. and PAPAZAFIRI, P. (2006). Anti-apoptotic effects of allopregnanolone on P19 neurons. Eur $J$ Neurosci 23: 43-54.

ZHAO, L.R., DUAN, W.M., REYES, M., KEENE, C.D., VERFAILLIE, C.M. and LOW W.C. (2002). Human bone marrow stem cells exhibit neural phenotypes and ameliorate neurological deficits after grafting into the ischemic brain of rats. Exp Neurol 174: 11-20. 


\section{Further Related Reading, published previously in the Int. J. Dev. Biol.}

See our recent Special Issue Fertilization, in honor of David L. Garbers and edited by Paul M. Wassarman and Victor D. Vacquier at: http://www.ijdb.ehu.es/web/contents.php?vol=52\&issue=5-6

The heart forming region of early chick embryo is an alternative source of embryonic stem cells Seema Borgave, Kirti Ghodke and Surendra Ghaskadbi Int. J. Dev. Biol. (2009) 53: 91-99

Genetic and epigenetic instability of human bone marrow mesenchymal stem cells expanded in autologous serum or fetal bovine serum

John-Arne Dahl, Shivali Duggal, Neralie Coulston, Douglas Millar, John Melki, Aboulghassem Shahdadfar, Jan E. Brinchmann and Philippe Collas

Int. J. Dev. Biol. (2008) 52: 1033-1042

From bone marrow to therapeutic applications: different behaviour and genetic/ epigenetic stability during mesenchymal stem cell expansion in autologous and foetal bovine sera?

Gaetana A. Tonti and Ferdinando Mannello

Int. J. Dev. Biol. (2008) 52: 1023-1032

An efficient method for isolation of murine bone marrow mesenchymal stem cells Samad Nadri, Masoud Soleimani, Reza H. HosSeni, Mohammad Massumi, Amir Atashi and Reza Izadpanah

Int. J. Dev. Biol. (2007) 51: 723-729

Enhanced development of porcine embryos cloned from bone marrow mesenchymal stem cells

Hai-Feng Jin, B. Mohana Kumar, Jung-Gon Kim, Hye-Jin Song, Yeon-Ji Jeong, Seong-Keun Cho, Sivasankaran Balasubramanian, Sang-Yong Choe and Gyu-Jin Rho Int. J. Dev. Biol. (2007) 51: 85-90

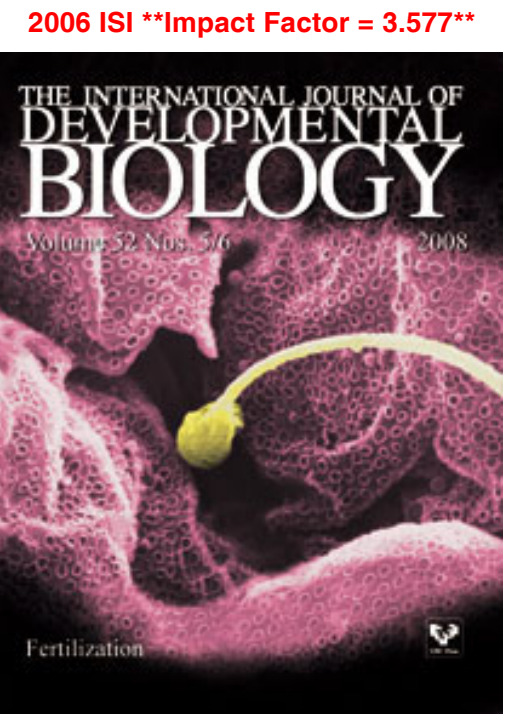

